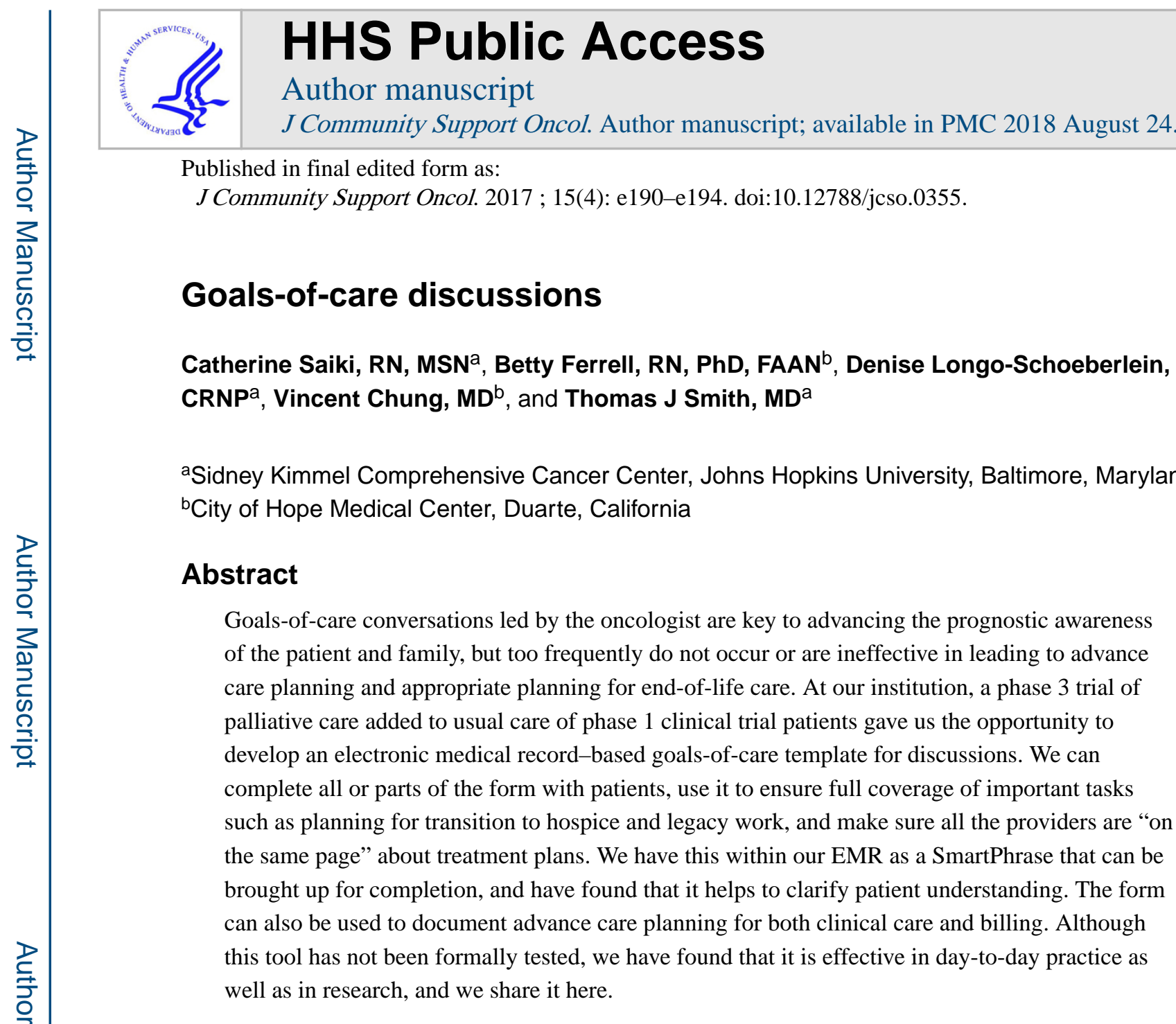

Goals-of-care conversations led by the oncologist are a key opportunity to improve advance care planning and end-of-life care, ${ }^{1}$ but our patients are not understanding the essentials. Findings from a study of patients' expectations about chemotherapy showed that more than two-thirds of patients with lung or colorectal cancers thought their palliative chemotherapy, ${ }^{2}$ radiation, ${ }^{3}$ and/or surgery ${ }^{4}$ could cure them. Failure to effectively educate patients can lead to end-of-life care associated with poor quality of care, including over-aggressive care, poor quality of life with suboptimal symptom management, caregiver distress, and other potentially preventable problems. ${ }^{5}$

Palliative care routinely includes goals-of-care (GoC) discussions as part of the standard note. At one large urban hospital, the 30-day readmission rate was $10 \%$ if palliative care consultation was done, compared with $15 \%$ if no consultation was obtained. ${ }^{6}$ Patients who had consultations that included GoC discussions in addition to a symptom management consultation had a lower hospital readmission rate of 5\%, compared with $15 \%$ in patients who received symptom management consultations alone (adjusted odds ratio [AOR], 0.36; confidence interval $[\mathrm{CI}], 0.27-0.48 ; P<.001) .{ }^{6}$ Findings from another study showed that

Correspondence: Thomas J Smith, MD; tsmit136@jhmi.edu.

Disclosures: The authors report no disclosures or conflicts of interest. 
the use of aggressive end-of-life care was reduced by one-third when the patient and provider had a GoC planning session close to the time of diagnosis, instead of at the end of life. $^{7}$

We prepared a template to be incorporated into the electronic medical record (EMR) to facilitate $\mathrm{GoC}$ discussions between the oncologist and patient as part of a randomized phase 3 trial of early versus delayed palliative care for phase 1 clinical trial patients.

Documentation is one of the most important elements of efforts to improve end-of-life care, along with advance care planning, $\mathrm{GoC}$ discussions, and understanding the system of care. ${ }^{8}$ Because we have found this approach useful in our everyday oncology practice, we are sharing this simple, doable template in the hope that others will find it effective.

\section{The GoC template}

\section{What does it look like?}

We developed a document for oncology $\mathrm{GoC}$ discussions that was incorporated into the EMR (Table). We use the GoC document in much the same way we'd review a computedtomography scan with our patients and their families: we bring it up on the computer screen, show them the categories, and type in responses on the allotted spaces on the right-hand side of the document. The input can be done in real time or after the conversation, or even after the patient has left. In our practice, we access the Patient Instructions part of the EMR, use a SmartPhrase to copy the Word template into the chart, and start typing.

The completed GoC sheet can be used in several ways. Most commonly, we print it out for the patient and family, so that everyone has access to the same information. Printing it out as part of the after-visit patient summary also satisfies the meaningful use requirement for EMRs. It is also possible to cut and paste the document into a letter to the care team, or directly into the Progress Note, so that it will be available for members of the care team to see.

The $\mathrm{GoC}$ form does take some time to complete. Palliative care teams that have reported on what was done during the palliative care visit have noted that the initial and subsequent visits took about an hour, with about 20 minutes devoted to symptom management, 15 minutes to patient and family coping, and 10 minutes to illness understanding and education, including prognosis. ${ }^{9}, 10$ In our own practice, we do questions 1-9 first (Table, shaded area) because it takes less time than anticipated, just like code status discussions, ${ }^{11}$ and it is much easier with a script.

We use this template for in- and out-patient consultations and for routine visits when a GoC discussion is warranted. It is important to remember that doing this counts as advance care planning and can be billed using the ACP codes.

\section{How do you use template?}

It is critically important to make sure that the patient and family are ready for this discussion. To further facilitate the discussion, we have devised a temporary palliative care tattoo with a script, or prompts, for what questions to ask and in what order they should be 
asked (Figure). The easy-to-read tattoo is worn on the inner forearm so that it is readily visible to the oncologist or advanced practice nurse. ${ }^{12}$

We always start by asking, "How do you like to get medical information?" (Table, question 1) and follow up with something like, "Are you the sort of person who wants all the details, or not?" (Table). If the response is yes, they want all the details, then we follow up with another question, "Does that include talking about prognosis and what might happen?" (Table). Most patients will want full disclosure of their circumstances and prognosis, but some will not, and will feel overwhelmed and disempowered if you proceed.

After reviewing the answers to question 1 and any follow-up questions you may have asked, you will be able to gauge whether you should continue with questions $2-4$ in the template. Once you know more about the patient and the family's understanding of the situation (Table, question 2), what is important to them (question 3), what they are hoping for (question 4), and have spoken to them about disease progression, recapped their treatment to date, and checked to see if they might be eligible for any clinical trials (question 5), it will be easier to move on to the next questions, about progressive disease and advance care planning: "You are doing OK now, but have you thought about a time when you could be sicker [and need] a living will or advance directive [question 6, see next section of this article]?" For people unwilling to have this discussion, or have it at that moment, there is an excellent article that outlines the process to help practitioners increase prognostic awareness. ${ }^{14}$ Patient readiness will change over time as they adjust to the life changes forced by serious illness, and one can put off the discussion until they are more accepting. Just remember that patients are not likely to broach the subject themselves, and part of our job is to offer guidance.

As Singh and colleagues have noted, many patients with incurable disease have poor "prognosis awareness," 15 so it is important for the oncologist to have a GoC conversation with the patient to be able to guage the patient's understanding of the prognosis after a scan that shows progressive disease. Singh and his colleagues reported that of 64 taped oncologist-patient conversations about scan results, only 4 included frank discussions about prognosis. The authors suggested asking the question, "Would you like to talk about what this means?" after showing the patient the scan to allow the patient some control and to get permission to disclose crucial information based on the reading of the scan. ${ }^{15}$

Getting started on the GoC discussions may be the hardest part. Some useful introductory lines might include: "In my experience, it is easier to talk about our goals of care while people are still doing well. I know the future can be more uncertain. That's why I want us to discuss these things now," or "I am worried about you, after looking at these scans. I think it is time to have another discussion about what the future holds."

\section{Starting the hospice information visit}

For patients with progressive disease, how do you know when to initiate a discussion about hospice and specifically, the hospice information visit, in a timely manner? It turns out oncologists are fairly adept at sensing when the prognosis has changed, but one useful tip is to routinely ask yourself the "surprise" question: "Would you be surprised if this patient 
were to die within the next 6 months?". ${ }^{16}$ We have developed this hospice information visit practice to ensure that hospice is brought up as part of a natural transition to end-of-life care. We have not formally tested the tool, but every oncologist we know who has adopted the practice has continued it.

If the answer to the "surprise" question is, "No, I would not be surprised if the patient were to die within 6 months," then we will make a referral to hospice for a hospice information visit. This allows for a timely, carefully planned transition to a known team, working with the oncologist, at some reasonably predictable point on the illness trajectory, usually while the patient is still on treatment. This transition can be difficult for patients and their families, and often they will voice concerns about feeling abandoned by the treating oncologist: "Dr Smith took care of us for seven years, and now - when Mom is the sickest and likely dying he is sending us to someone whom we have never met before." The timing of this transition is important, because the tendency is to delay for as long as possible, as demonstrated in a study by O'Connor and colleagues of admissions to hospice, which found that $16 \%$ of cancer patients were on hospice for 3 days or less. ${ }^{17}$

After we have discussed hospice care with the patient, we ask the hospice team to call the patient to set up the hospice information visit. We have been surprised to see that most patients, after the initial shock of talking about hospice care, have indicated that they found this planned transition visit with the hospice team informative and helpful.

One way in which you could broach the topic of hospice care with a patient to avoid the feelings of abandonment, is to say, "I want you to meet the people who will be helping me take care of you if and when we need them." This emphasizes the continuity of care and the desire for a smooth, planned transition. We try to do this when we think the patient has about 6 months to live. Then, when the patient's performance status changes or the disease progresses, we will activate the referral and will say, "Remember nurse Bob and the social worker Clare who came out to your house 3 months ago? I think it's time we touch base with them again. It's time to change goals from fighting the cancer to maintaining your quality of life. In my experience, hospice support will help us do just that."

Adelson and colleagues developed standardized criteria (triggers or prompts) for use in palliative care consultation to help improve overall quality of care. ${ }^{18}$ The criteria included any solid tumor patient with: stage IV solid malignancy or stage III lung or pancreatic cancer; a hospitalization of $>7$ days; hospitalized in the last 30 days (not including routine chemotherapy); and uncontrolled symptoms (pain, nausea/vomiting, dyspnea, delirium, psychological distress). The investigators showed that use of the standardized criteria for palliative care consultation was associated with a decline in 30-day readmission rates (35\% for the intervention group, $13 \%$ for the control group), the use of chemotherapy after discharge (18\% and $44 \%$, respectively), and use of support services after discharge.

\section{Discussion}

We see this approach with GoC discussions as part of our TEAM approach (Time, Education, Assessment, and Management) to care ${ }^{19}$ that is patient and family centered, 
education centered, and symptom centered. Other institutions where similar prompt systems have been used have also shown improvements in advance care planning. Temel and colleagues found in a 2010 retrospective review of the EMRs and longitudinal medical records of 2,498 patients with metastatic cancer that only $20 \%$ patients had a documented code status, despite their advanced disease state. ${ }^{20} \mathrm{~A}$ second study at the same institution, also by Temel and colleagues, showed that during 2009-2011, e-mail prompts encouraging physicians to document their patients' code status resulted in a doubling of the rate of code status documentation, from $14.5 \%$ for historical controls to $33.7 \%$ after introducing the prompt system. ${ }^{21}$

In a study of a disease-management pilot program in Medicare patients with cancer, US Oncology adopted the best practice model of appointing someone in the practice, usually a nurse, to review advance care planning within the first visits of diagnosis of a life-limiting illness, and increased advance care planning to more than $80 \% .{ }^{22}$ In another US Oncology study, Neubauer and colleagues reported that the implementation of an ACP process at 38 member sites resulted in a $15.6 \%$ increase in the incidence of code status documentation, and although the incidence of documentation varied considerably, it was as high as $89 \%$ at some sites. ${ }^{23}$

For how long should a terminally ill cancer patient be enrolled in hospice? Von Gunten has suggested increasing length of stay (LoS) in hospice as a quality improvement task. He reported on a study in which oncologists in Ohio were given the LoS recommendations from the state's Oncology Clinical Guidance Council (LoS, 45-90 days), the national LoS average (43 days), and their peers (19.7 days) at baseline, including a chart showing the median LoS by oncologist. Follow-up with the medical oncologist after a year, showed that there was a doubling of hospice LoS, from the baseline 19.7 days to 39.6 days. $^{24}$

Patients who have timely end-of-life discussions addressing GoC and understanding of their illness, are more likely to be satisfied with their quality of care, receive care that is closer to their stated preferences, and die at the place of their choosing, and their family members will be less distressed. ${ }^{25}$ In addition, Enzinger and colleagues have shown that patients who had prognostic discussions with their oncologists revised their self-reported estimates of their survival downward by 17.2 months, which brought them closer to a more realistic expectation of life expectancy, without having a negative impact on their emotional wellbeing (sadness, anxiety) or relationship with the physician. ${ }^{26}$ However, it is important to remember, that we, as the oncologist, have to start the GoC, hospice, and EoL conversations, because patients understandably rarely bring it up of their own free will.

\section{References}

1. Bernacki RE, Block SD. American College of Physicians High Value Care Task Force. Communication about serious illness care goals: a review and synthesis of best practices. JAMA Intern Med. 2014; 174(12):1994-2003. [PubMed: 25330167]

2. Weeks JC, Catalano PJ, Cronin A, et al. Patients' expectations about effects of chemotherapy for advanced cancer. N Engl J Med. 2012; 367(17):1616-25. [PubMed: 23094723]

3. Chen AB, Cronin A, Weeks JC, et al. Expectations about the effectiveness of radiation therapy among patients with incurable lung cancer. J Clin Oncol. 2013; 31(21):2730-2735. [PubMed: 23775958] 
4. Kim Y, Winner M, Page A, et al. Patient perceptions regarding the likelihood of cure after surgical resection of lung and colorectal cancer. Cancer. 2015; 121(20):3564-3573. [PubMed: 26094729]

5. Wright AA, Zhang B, Ray A, et al. Associations between end-of-life discussions, patient mental health, medical care near death, and caregiver bereavement adjustment. JAMA. 2008; 300(14): 1665-1673. [PubMed: 18840840]

6. O'Connor NR, Moyer ME, Behta M, Casarett DJ. The impact of inpatient palliative care consultations on 30-day hospital readmissions. J Palliat Med. 2015; 18(11):956-961. [PubMed: 26270277]

7. Ahluwalia SC, Tisnado DM, Walling AM, et al. Association of early patient-physician care planning discussions and end-of-life care intensity in advanced cancer. J Palliat Med. 2015; 18(10):834-841. [PubMed: 26186553]

8. Sinuff T, Dodek P, You JJ, et al. Improving end-of-life communication and decision making: the development of a conceptual framework and quality indicators. J Pain Symptom Manag. 2015; 49:1070-1080.

9. Jacobsen J, Jackson V, Dahlin C, et al. Components of early outpatient palliative care consultation in patients with metastatic nonsmall cell lung cancer. J Palliat Med. 2011; 14(4):459-464. [Behind paywall]. [PubMed: 21417739]

10. Jorgenson A, Sidebottom AC, Richards H, Kirven J. A description of inpatient palliative care actions for patients with acute heart failure. Am J Hosp Palliat Care. 2016; 33(9):863-870. [Behind paywall]. [PubMed: 26126817]

11. Smith TJ, Desch CE, Hackney MH, Shaw JE. How long does it take to get a 'do not resuscitate' order? J Palliat Care. 1997; 13(1):5-8. Available only as PDF on interlibrary loan.

12. Leong M, Shah M, Smith TJ. How to avoid late chemotherapy. J Oncol Pract. 2016; 12(12):12081210. [PubMed: 27650845]

13. Spencer JC, Wheeler SB. A systematic review of motivational interviewing interventions in cancer patients and survivors. Patient Educ Couns. 2016; 99(7):1099-1105. [Behind paywall]. [PubMed: 26879805]

14. Jackson VA, Jacobsen J, Greer JA, Pirl WF, Temel JS, Back AL. The cultivation of prognostic awareness through the provision of early palliative care in the ambulatory setting: a communication guide. J Palliat Med. 2013; 16(8):894-900. [Behind paywall]. [PubMed: 23786425]

15. Singh S, Cortez D, Maynard D, Cleary JF, DuBenske L, Campbell TC. Characterizing the nature of scan results discussions: insights into why patients misunderstand their prognosis. J Oncol Pract. 2017; 13(3):e231-e239. [Behind paywall]. [PubMed: 28095172]

16. Gómez-Batiste X, Martínez-Muñoz M, Blay C. , et al. [Accessed August 4, 2017] Utility of the NECPAL CCOMS-ICOC tool and the Surprise Question as screening tools for early palliative care and to predict mortality in patients with advanced chronic conditions: A cohort study. [Behind paywall]http://journals.sagepub.com/doi/abs/10.1177/0269216316676647. Published online November 4, 2016

17. O'Connor NR, Hu R, Harris PS, Ache K, Casarett DJ. Hospice admissions for cancer in the final days of life: independent predictors and implications for quality measures. J Clin Oncol. 2014; 32(28):3184-3179. [PubMed: 25154824]

18. Adelson K, Paris J, Horton JR, et al. Standardized criteria for palliative care consultation on a solid tumor oncology service reduces downstream health care use. J Oncol Pract. 2017; 13(5):e431e440. [Behind paywall]. [PubMed: 28306372]

19. Bakitas MA, El-Jawahri A, Farquhar M, et al. The TEAM approach to improving oncology outcomes by incorporating palliative care in practice. J Onc Pract. In press.

20. Temel JS, Greer JA, Admane S, et al. Code status documentation in the outpatient electronic medical records of patients with metastatic cancer. J Gen Intern Med. 2010; 25(2):150-153. [PubMed: 19894078]

21. Temel JS, Greer JA, Gallagher ER, et al. Electronic prompt to improve outpatient code status documentation for patients with advanced lung cancer. J Clin Oncol. 2013; 31(6):710-715. [PubMed: 23284038] 
22. Neubauer MA, Hoverman RA, Jameson M. , et al. [Accessed August 4, 2016] A disease management pilot program in a Medicare-age population with cancer [abstract 6505]. http:// ascopubs.org/doi/abs/10.1200/JCO.2016.34.15_suppl.6505. Published May 2016

23. Neubauer MA, Taniguchi CB, Hoverman JR. Improving incidence of code status documentation through process and discipline. J Oncol Pract. 2015; 11(2):e263-e266. [PubMed: 25784582]

24. Von Gunten CF. [Accessed August 4, 2017] A quality improvement approach to oncologist referrals for hospice care. http://ascopubs.org/doi/abs/10.1200/jco.2016.34.26_suppl.4. Published October 2016

25. Kumar P, Temel JS. End-of-life care discussions in patients with advanced cancer. J Clin Oncol. 2013; 31(27):3315-3319. [PubMed: 23897952]

26. Enzinger AC, Zhang B, Schrag D, Prigerson HG. Outcomes of prognostic disclosure: associations with prognostic understanding, distress, and relationship with physician among patients with advanced cancer. J Clin Oncol. 2015; 33(32):3809-3816. [PubMed: 26438121]

27. Varon J, Walsh GL, Marik PE, Fromm RE. Should a cancer patient be resuscitated following an inhospital cardiac arrest? Resuscitation. 1998; 36(3):165-168. [PubMed: 9627066]

28. Wallace S, Ewer MS, Price KJ, Feeley TW. Outcome and cost implications of cardiopulmonary resuscitation in the medical intensive care unit of a comprehensive cancer center. Support Care Cancer. 2002; 10(5):425-429. [PubMed: 12136227] 
1. How do you like to get medical information?

2. What is your understanding of your situation?

3. What is important to you?

4. What are you hoping for?

5. Have you thought about a time when you could be sicker., . Living Will or advance directive?

FIGURE.

A temporary tattoo can be used as a script or prompt for starting difficult conversations with patients about diagnosis, progressive disease, and hospice and end-of-life care. It is placed on the practitioner's inner forearm so that it can be easily read. 


\section{TABLE}

Goals-of-care discussion template for EPIC, Cerner, or other electronic medical records

Goals of Care: Fill in the patient responses onscreen in the allotted space on the right as you conduct the interview, then print it out for the patient and family. The interview can be done over several visits if needed, and updated as the situation changes. Fulfills meaningful use. Start with the questions in the shaded cells. You can always come back next visit and restart.

Patient information preferences, understanding, priorities, and hopes

1. How do you like to get medical information?

- $\quad$ Full or something else?

- How about prognosis?

2. What is your understanding of your situation?

3. What is important to you?

4. What are you hoping for?

Progressive disease

5. If the disease is growing, acknowledge that not all things have a medical fix:

- $\quad$ Ask, 'Would you like to discuss what the scan findings mean?'

- List the prior treatments and response to them, to give them a record of what has been done. It may be important for families know they have not left any medical stones unturned.

- $\quad$ Explore if the patient might be eligible for any clinical trials.

Advance care planning

6. Do you have a will? [Safe starter question.]

7. Do you have a Living Will or advanced directive or portable orders for lifesustaining treatments? [eg, POLST] If yes, ask:

- Are all of your providers aware of the wishes and proxy for your medical care that are stated in these documents?

- Are documents readily available in your electronic health records and for all of your health care providers?

- $\quad$ Check what it says about CPR. [The success rate of CPR is low for patients in hospital who are dying of cancer. ${ }^{27,28}$ ]

\section{Health care proxy}

8. Who do you want to make medical decisions, if you can't?

9. Have you discussed this with her/him?

Spiritual, family, financial matters

10. Are there spiritual issues to be settled?

11. Are there family issues to be settled?

12. Are there financial issues to be settled?

Hospice and end-of-life care discussion 
13. Have you met with hospice yet? [Plan for at least 3-6 months before death, which is predictable for most diseases. This really helps the transition if and when hospice is needed.]

14. Have you thought about where you would like to be for your death, if and when?

15. Legacy work

- Let's start doing a life review - what you want people to remember about you.

- What's important to you?

- What are you hoping for?

- What do you want to accomplish in the time you have left?

Daily living, provider contact information

16. Living day to day

Exercise

Supplements

Other instructions

Office

Nights

e-mail
Diet

Mindfulness

Days

Cell

MyChart 